\title{
Analisa Tingkat Pencemaran Air pada Sumur Gali Rt 15, Desa Bangun Rejo, Kecamatan Tenggarong Seberang
}

\author{
Analysis of Water Pollution Level in Dug Well RT 15, Bangun Rejo Village, \\ Tenggarong Seberang Sub-District \\ Kemala Hadidjah \\ Program Studi Pengelolaan Lingkungan Politeknik Pertanian Negeri Samarinda \\ Jalan Samratulangi PoBox 192 Samarinda 75131, Indonesia \\ Correspondence author: kemalahadidjah@gmail.com
}

\begin{abstract}
ABSTRAK
Kondisi sumur gali di RT 15 Desa Bangun Rejo, Kecamatan Tenggarong Seberang ini memiliki kedalaman yang berbeda-beda dan warna tidak jernih ditemukan di sebagian sumur yang ada. Masyarakat sekitar masih memakai sumur untuk mencuci dan mandi. Sedangkan untuk konsumsi lebih memakai air dari PDAM atau mereka membeli dari depo air di sekitar desa. Tujuan dilakukannya penelitian ini adalah untuk mengetahui kualitas air dilihat dari parameter Potential Of Hydrogen $(\mathrm{pH})$, kekeruhan dan Total Dissolved Solids (TDS) pada air sumur gali di RT 15 Desa Bangun Rejo, Kecamatan Tenggarong Seberang. Metode yang dilakukan adalah mempersiapkan penelitian di lapangan dan di laboratorium. Sampel air sumur gali diambil dan langsung dibawa ke laboratorium untuk dilakukan analisis TDS, kekeruhan dan $\mathrm{pH}$. Proses analisa $\mathrm{pH}$ dengan menggunakan alat $\mathrm{pH}$ meter, analisa kekeruhan menggunakan alat Turbidity Meter, dan analisis TDS menggunakan alat Conductivity Pocket Meter. Dari hasil penelitian menunjukkan bahwa ratarata nilai $\mathrm{pH}$ dari 7 sampel air sumur gali adalah 6,15 ; rata-rata nilai TDS adalah $237,14 \mathrm{mg} / \mathrm{L}$ dan nilai ratarata kekeruhan adalah 45,80 NTU; dimana pada masing-masing parameter dilakukan 2 kali pengulangan. Standar baku mutu air berdasarkan Peraturan Menteri Kesehatan RI Nomor : 416/MENKES/PER/IX/1990 Tentang Syarat-Syarat dan Pengawasan Kualitas Air menunjukkan bahwa nilai kadar maksimum yang diperbolehkan untuk kekeruhan $25 \mathrm{NTU}, \mathrm{pH}$ 6,5 - 9,0 dan TDS $1.500 \mathrm{mg} / \mathrm{L}$. Dari ketiga parameter ini, dapat disimpulkan bahwa sumur gali di RT 15 Desa Bangun Rejo, Kecamatan Tenggarong Seberang, masih belum sepenuhnya tercemar.
\end{abstract}

Kata Kunci : pH, Kekeruhan, TDS, Sumur Gali.

\section{ABSTRACT}

The condition of dug wells at RT 15, Bangun Rejo Village, Tenggarong Seberang Sub-District has different depths and unclear colors were found in some of the wells. The surrounding community still uses wells for washing and bathing. As for consumption, they use water from the PDAM or buy it from water depots around the village. The purpose of this study was to determine water quality based on the parameters of Potential of Hydrogen ( $\mathrm{pH}$ ), turbidity and total dissolved solids (TDS) in dug well water in RT 15, Bangun Rejo Village, Tenggarong Seberang Sub-District. This research was conducted in the field and the laboratory. Dug well water samples are taken and directly sent to the laboratory for analysis of TDS, turbidity and $\mathrm{pH}$. The process of analyzing $\mathrm{pH}$ using a $\mathrm{pH}$ meter, turbidity analysis using a Turbidity Meter, and TDS analysis using a Conductivity Pocket Meter. The results showed that the average $\mathrm{pH}$ value of 7 dug well water samples was 6,15; the average TDS value was $237,14 \mathrm{mg} / \mathrm{L}$ and the average turbidity value was 45,80 NTU; where for each parameter 2 repetitions are performed. Water quality standards based on the Regulation of the Minister of Health of the Republic of Indonesia Number: 416/MENKES/PER/IX/1990 Concerning Water Quality Requirements and Monitoring shows that the maximum permissible value for turbidity is $25 \mathrm{NTU}, \mathrm{pH}$ 6,5 - 9,0 and TDS $1.500 \mathrm{mg} / \mathrm{L}$. From these three parameters, it can be concluded that the dug well in RT 15, Bangun Rejo Village, Tenggarong Seberang Sub-District, is still not completely polluted.

Keywords : $p H$, turbidity, TDS, dug well.

\section{PENDAHULUAN}

Air merupakan kebutuhan yang sangat penting dalam kehidupan, karena semua mahluk hidup di dunia ini membutuhkan air. Air dimanfaatkan oleh manusia untuk berbagai kebutuhan hidup sehari-hari.
Kebutuhan air untuk setiap individu berbedabeda untuk tiap tempat dan tiap tingkat kebutuhan. Semakin tinggi taraf kehidupan di suatu tempat, maka semakin meningkat pula jumlah kebutuhan akan air. Ada berbagai macam sumber air yang dapat dimanfaatkan oleh manusia,antara lain air laut, air hujan, air 
permukaan (sungai, rawa, danau) dan air tanah dan salah satunya adalah sumur gali.

Sumur gali merupakan salah satu sumber penyediaan air bersih bagi masyarakat di pedesaan, maupun perkotaan. Sumur gali menyediakan air yang berasal dari lapisan tanah yang relatif dekat dengan permukaan tanah, oleh karena itu mudah terkena kontaminasi melalui rembesan yang berasal dari kotoran manusia, hewan, maupun untuk keperluan domestik rumah tangga. Sumur gali sebagai sumber air bersih harus ditunjang dengan syarat konstruksi, syarat lokasi untuk dibangunnya sebuah sumur gali, hal ini diperlukan agar kualitas air sumur gali aman sesuai dengan aturan yang ditetapkan (Katiho dkk, 2013).

Berdasarkan Peraturan Menteri Kesehatan No 416/MEN.KES/PER/IX/1990 tentang syarat-syarat Baku Mutu dan pengawasan kualitas air yang disebut sebagai air bersih adalah air yang digunakan untuk keperluan sehari-hari yang kualitasnya memenuhi syarat kesehatan dan dapat diminum apabila telah dimasak.

Kehidupan di alam ini berkepentingan kepada air. Oleh karena itu, perlindungan terhadap kulaitas air sangat penting dan berpengaruh besar terhadap tingakat kesehatan mahluk hidup dan peningkatan lingkungan hidup yang sehat. Untuk menjaga atau mencapai kualitas tersebut, yaitu kualitas air yang dapat dimanfaatkan secara berkelanjutan sesuai dengan mutu air yang diinginkan, maka perlu upaya pelestarian untuk memelihara fungsi air sehingga kualitasnya memenuhi baku mutu yang ditetapkan. Namun sering dijumpai bahwa banyak penduduk yang terpaksa memanfaatkan air yang kurang baik kualitasnya. Tentu saja hal ini dapat menimbulkan dampak negatif bagi kesehatan masyarakat baik pada jangka pendek maupun pada jangka panjang (Suryana, 2013).

Daerah di Desa Bangun Rejo adalah desa transmigrasi yang penduduknya ratarata dari Jawa. Kondisi air sumur gali di desa ini ada yang sebagian tempat memiliki kedalaman yang berbeda-beda dan warna tidak jernih ditemukan di sebagian sumur yang ada. Sumur memiliki kedalaman yang berbeda-beda. Masyarakat sekitar masih memakai sumur untuk mencuci dan mandi. Sedangkan untuk konsumsi lebih memakai air dari PDAM atau mereka membeli dari depo air isi ulang di sekitar desa.

Penelitian ini bertujuan untuk mengetahui nilai kekeruhan, $\mathrm{pH}$, dan TDS pada beberapa sumur gali di RT 15 Desa Bangun Rejo Kecamatan Tenggarong Seberang. Dan dari hasil tersebut diharapkan dapat memberikan informasi kepada masyarakat Desa Bangun Rejo Kecamatan Tenggarong Seberang tentang kualitas air sumur gali yang ada di daerah tersebut serta dapat menjadi referensi bagi penelitian selanjutnya tentang sumur dalam.

\section{BAHAN DAN METODE}

Penelitian ini dilakukan di beberapa sumur gali yang ada di RT 15 Desa Bangun Rejo Kecamatan Tenggarong Seberang. Pengambilan sampel air sumur gali dilakukan di 7 sumur gali dari total 20 sumur gali yang ada. Pengukuran parameter $\mathrm{pH}$ langsung dilakukan di lapangan, sedangkan pengukuran kekeruhan dan TDS dilakukan di Laboratorium Tanah dan Air Politeknik Pertanian Negeri Samarinda. Penelitian ini dilaksanakan pada bulan Juli 2019.

Bahan dan peralatan yang digunakan diantaranya yaitu :

a. Alat : Botol Sampel (jerigen plastik), APD (Alat Pelindung Diri), Gelas, Kamera Digital, $\mathrm{pH}$ Meter, Turbidity Meter, Conductivity Pocket Meter

b. Bahan : Air Sampel Sumur Gali

Prosedur penelitian ini meliputi beberapa tahapan sebagai berikut :

a. Survei lokasi

Survei dilakukan untuk melihat lokasi dan menentukan titik pengambilan sampel.

b. Pengambilan Sampel

Dari kegiatan survei lokasi, terdapat 20 sumur yang memiliki kedalaman 3-4 meter yang tersebar di RT 15 Desa Bangun Rejo Tenggarong Seberang, dalam kegiatan pengambilan sampel di 20 sumur diperkecil menjadi 7 sumur. Pengambilan sampel diperkecil menjadi 7 sumur karena jarak antara sumur satu dengan yang lain berdekatan dan daerah resapan yang sama. Apabila sampel sumur yang diambil berdekatan tidak akan berpengaruh atau hasil yang didapat sama.

c. Analisis Sampel 
Sampel yang sudah diambil kemudian dianalisis kandungan $\mathrm{pH}-n y a$, dan dilakukan secara langsung di lapangan. Sedangkan untuk parameter kekeruhan dan TDS dilakukan di Laboratorium Tanah dan Air Politeknik Pertanian Negeri Samarinda. Metode yang digunakan untuk mengukur parameter kekeruhan adalah dengan metode transmisi cahaya dan menggunakan alat Turbidity Meter. Sedangkan metode yang digunakan untuk mengukur TDS adalah dengan metode electrical conductivity dengan menggunakan alat Conductivity Conduct Meter. d. Pengambilan sampel air sumur gali

Pengambilan sampel air sumur gali dilakukan pada 7 titik dan dilakukan 2 kali pengulangan.

\section{HASIL DAN PEMBAHASAN}

Hasil analisis secara langsung terhadap parameter $\mathrm{pH}$ maupun hasil analisis laboratorium terhadap kekeruhan dan TDS pada air sumur gali yang berasal dari 7 titik dan 2 kali pengulangan dapat dilihat pada Tabel 1.

Tabel 1. Hasil Analisis pH, kekeruhan dan TDS air sumur gali Desa Bangun Rejo Kecamatan Tenggarong Seberang

\begin{tabular}{|c|c|c|c|c|}
\hline Parameter & Hasil Pengukuran & Satuan & Keterangan & $\begin{array}{c}\text { Standar } \\
\text { Baku Mutu* }\end{array}$ \\
\hline \multirow{7}{*}{$\mathrm{pH}$} & 5,82 & - & Tidak sesuai baku mutu & \multirow{7}{*}{$6,5-9$} \\
\hline & 6,13 & - & Tidak sesuai baku mutu & \\
\hline & 5,86 & - & Tidak sesuai baku mutu & \\
\hline & 6,20 & - & Tidak sesuai baku mutu & \\
\hline & 6,79 & - & Sesuai baku mutu & \\
\hline & 6,26 & - & Tidak sesuai baku mutu & \\
\hline & 5,99 & - & Tidak sesuai baku mutu & \\
\hline \multirow{7}{*}{ TDS } & 455,5 & $\mathrm{mg} / \mathrm{L}$ & Sesuai baku mutu & \multirow{7}{*}{$\begin{array}{l}\text { Maksimal } \\
1500 \mathrm{mg} / \mathrm{L}\end{array}$} \\
\hline & 335,75 & $\mathrm{mg} / \mathrm{L}$ & Sesuai baku mutu & \\
\hline & 180,5 & $\mathrm{mg} / \mathrm{L}$ & Sesuai baku mutu & \\
\hline & 158,5 & $\mathrm{mg} / \mathrm{L}$ & Sesuai baku mutu & \\
\hline & 180,75 & $\mathrm{mg} / \mathrm{L}$ & Sesuai baku mutu & \\
\hline & 158,5 & $\mathrm{mg} / \mathrm{L}$ & Sesuai baku mutu & \\
\hline & 194,5 & $\mathrm{mg} / \mathrm{L}$ & Sesuai baku mutu & \\
\hline \multirow{7}{*}{ Kekeruhan } & 151 & NTU & Tidak sesuai baku mutu & \multirow{7}{*}{$\begin{array}{c}\text { Maksimal } \\
25 \text { NTU }\end{array}$} \\
\hline & 1,51 & NTU & Sesuai baku mutu & \\
\hline & 4,98 & NTU & Sesuai baku mutu & \\
\hline & 18,3 & NTU & Sesuai baku mutu & \\
\hline & 66,6 & NTU & Tidak sesuai baku mutu & \\
\hline & 63 & NTU & Tidak sesuai baku mutu & \\
\hline & 15,2 & NTU & Sesuai baku mutu & \\
\hline
\end{tabular}


Sumur gali adalah satu konstruksi sumur yang paling umum dan meluas yang dipergunakan untuk mengambil air tanah bagi masyarakat kecil dan rumah-rumah perorangan sebagai air minum dengan kedalaman 7-10 meter dari permukaan tanah. Sumur gali menyediakan air yang berasal dari lapisan tanah yang relatif dekat dari permukaan tanah, oleh karena itu dengan mudah terkena kontaminasi melalui rembesan. Umumnya rembesan berasal dari tempat buangan kotoran manusia (kakus/jamban) dan hewan, juga dari limbah sumur itu sendiri, baik karena lantainya maupun saluran air limbahnya yang tidak kedap air.

Keadaan konstruksi dan cara pengambilan air sumur pun dapat merupakan sumber kontaminasi, misalnya sumur dengan konstruksi terbuka dan pengambilan air dengan timba. Sumur dianggap mempunyai tingkat perlindungan sanitasi yang baik, bila tidak terdapat kontak langsung antara manusia dengan air di dalam sumur (Depkes RI, 2005).

Keberadaan sumber air ini harus dilindungi dari aktivitas manusia ataupun hal lain yang dapat mencemari air. Sumber air ini harus memiliki tempat (lokasi) dan konstruksi yang terlindungi dari drainase permukaan dan banjir. Bila sarana air bersih ini dibuat dengan memenuhi persyaratan kesehatan, maka diharapkan pencemaran dapat dikurangi, sehingga kualitas air yang diperoleh menjadi lebih baik (Waluyo, 2005). Dari segi kesehatan penggunaan sumur gali ini kurang baik bila cara pembuatannya tidak benar-benar diperhatikan, tetapi untuk memperkecil kemungkinan terjadinya pencemaran dapat diupayakan pencegahannya, pencegahan-pencegahan ini dapat dipenuhi dengan memperhatikan syarat-syarat fisik dari sumur tersebut yang didasarkan atas kesimpulan dari pendapat beberapa pakar di bidang ini, diantaranya lokasi sumur tidak kurang dari 10 meter dari sumber pencemar, lantai sumur sekurangkurang berdiameter 1 meter jaraknya dari dinding sumur dan kedap air, saluran pembuangan air limbah minimal 10 meter dan permanen, tinggi bibir sumur 0,8 meter, memiliki cincin (dinding) sumur minimal 3 meter dan memiliki tutup sumur yang kuat dan rapat (Indan, 2003).
Hasil pengamatan secara visual di lapangan diperoleh fakta bahwa ada beberapa sampel air sumur gali yang berwarna kecoklatan (keruh). Selain dilakukannya pengamatan warna (kekeruhan), dilakukan pula analisis kekeruhan di laboratorium. Hasil rata-rata kekeruhan di sumur A 151 NTU, sumur B 1,51 NTU, sumur C 4,98 NTU, sumur D 18,3 NTU, sumur E 66,6 NTU, sumur F 63 NTU, dan sumur G 15,2 NTU. Pemeriksaan nilai parameter kekeruhan di laboratorium menguatkan hasil pengamatan secara langsung di lapangan. Kekeruhan menggambarkan sifat optik air yang ditentukan berdasarkan banyaknya cahaya yang diserap dan dipancarkan oleh bahanbahan yang terdapat didalam air. Hal ini dapat disebabkan adanya bahan organik dan anorganik yang tersuspensi dan terlarut, maupun bahan anorganik dan organik yang berupa plankton dan mikroorganisme lain.

Selain melakukan pengamatan kekeruhan secara langsung di lapangan, pengukuran nilai parameter $\mathrm{pH}$ juga dilakukan secara langsung di lapangan; yang menunjukkan nilai rata-rata $\mathrm{pH}$ di sumur $\mathrm{A}$ 5,82 ; sumur $B$ 6,13; sumur $C 5,86$; sumur $D$ 6,20 ; sumur $E$ 6,79; sumur $F 6,26$; dan sumur $\mathrm{G} 5,99$. Berdasarkan analisis $\mathrm{pH}$ air sumur gali di Desa Bangun Rejo masih memenuhi baku mutu Peraturan Menteri Kesehatan No 416/MEN.KES/PER/IX/1990 tentang air bersih. Dari ketujuh sumur gali yang diambil sampelnya, rata-rata air sumur gali tersebut bersifat asam. Letak sumur berdekatan dengan kolam pembuangan air limbah rumah tangga seperti air buangan cuci piring dan baju, sampah-sampah organik yang berasal dari pohon yang ada di sekitar sumur. Hal ini menyebabkan $\mathrm{pH}$ pada air sumur tersebut bersifat asam. Limbah atau sampah seperti buangan deterjen mengandung senyawa kimia yang dapat meningkatkan $\mathrm{pH}$. Kondisi air sumur gali yang telah diuji termasuk $\mathrm{pH}$ rendah atau bersifat asam yang tidak dapat digunakan. Asam adalah zat yang dalam air melepaskan ion $\mathrm{H}^{+}$, sedangkan Basa adalah zat yang dalam air melepaskan ion $\mathrm{OH}^{-}$. Air yang bersifat asam dapat menyebabkan korosif, jika air sumur ini digunakan untuk sehari-hari dan untuk minum dapat menyebabkan masalah otak dan syaraf, menurunnya kemampuan pendengaran, gangguan pada kulit seperti luka dan gatal- 
gatal, serta dapat menyebabkan keguguran pada wanita hamil. Air yang asam juga dapat menyebabkan kerusakan terhadap wadah penampungan air, pipa, bahkan dapat merusak pakaian jika digunakan untuk mencuci pakaian (Hasrianti dan Nurasia, 2013).

Disamping parameter $\mathrm{pH}$ dan kekeruhan, dilakukan juga pengukuran parameter TDS terhadap air sumur gali di Desa Bangun Rejo. Hasil pengukuran parameter TDS di laboratorium menunjukkan bahwa nilai TDS di sumur A $455,5 \mathrm{mg} / \mathrm{L}$; sumur B 335,75 mg/L; sumur C 180,5 mg/L; sumur D 158,5 mg/L; sumur E 180,75 mg/L; sumur F 158,5 mg/L; dan sumur G 194,5 $\mathrm{mg} / \mathrm{L}$. Dari semua sumur yang diambil sampelnya, nilai parameter TDSnya masih di bawah standar baku mutu yang diijinkan, yaitu sebesar $1500 \mathrm{mg} / \mathrm{L}$. Zat padat adalah material tersuspensi atau terlarut dalam air yang dapat mempengaruhi kualitas air. Bila TDS bertambah maka kesadahan akan naik pula. TDS akan mempengaruhi daya hantar listrik. Semakin banyak ion bermuatan listrik maka akan mempengaruhi dan mempermudah daya hantar listrik dan selain itu TDS menyebabkan kekeruhan (turbidity) serta mempengaruhi salinitas karena senyawa terlarut menyebabkan air menjadi asin (Djuhariningrum, 2005). Total padatan terlarut merupakan bahan-bahan terlarut dalam air yang tidak tersaring dengan kertas sari millipore dengan ukuran pori 0,45 $\mu \mathrm{m}$. padatan ini terdiri dari senyawa-senyawa anorganik dan organik yang terlarut dalam air, mineral dan garam-garamnya (Soemirat, 2009).

\section{KESIMPULAN}

Pengambilan sampel air sumur gali yang telah dilakukan pengukuran $\mathrm{pH}$ menunjukkan bahwa air sumur gali tersebut bersifat asam. Jika diamati secara visual, warna dari air sumur gali tersebut adalah kecoklatan, hal ini diperkuat dengan pengukuran parameter kekeruhan yang dilakukan di laboratorium. Akan tetapi ketika dilakukan pengukuran parameter TDS, nilainya masih dibawah ambang baku mutu yang diijinkan.

Didapatkan $\mathrm{pH}$ air yang bersifat asam karena secara garis besar, Pulau Kalimantan merupakan pulau yang memiliki lahan gambut yang sangat luas dan kondisi hidrologi Kalimantan umumnya sangat dipengaruhi oleh lahan gambut, dimana hutan rawa gambut dalam kondisi murni air tawar memiliki karakteristik kimiawi yang khas, airnya sangat asam dan unsur haranya sangat rendah. Sedangkan air sumur gali rata-rata berwarna kecoklatan (parameter kekeruhan), karena adanya bahan organik dan anorganik yang tersuspensi dan terlarut, maupun bahan anorganik dan organik yang berupa plankton dan mikroorganisme lain. Untuk parameter TDS, air sumur gali di Desa Bangun Rejo masih dibawah batas ambang yang diijinkan dan dapat digunakan untuk kegiatan sehari-hari seperti mencuci, mandi, dan lain-lain jika dilakukan dengan cara yang benar.

Berdasarkan kesimpulan penelitian yang telah dikemukakan, maka dapat disarankan bahwa; jika masayarakat sekitar ingin menggunakan air sumur untuk kebutuhan sehari-hari, khususnya sebagai air bersih, agar terlebih dahulu memperhatikan kandungan/kadar serta kualitas dari air tersebut.

\section{DAFTAR PUSTAKA}

Depkes RI. 2005. Undang-Undang Republik Indonesia Nomor 23 Tahun 2005 Tentang Kesehatan. Fisioterapi Indonesia. Jakarta.

Djuhariningrum, T. 2005. Penentuan Total Zat Padat Terlarut Dalam Memprediksi Kualitas Air Tanah Dari Berbagai Contoh Air (Jurnal). Pusat Pengembangan Geologi Nuklir Batan.

Hasrianti dan Nurasia. 2013. Analisis Warna, Suhu, pH, Salinitas Air Sumur Bor Di Kota Palopo. Volume 02 Nomor 1. Universitas Cokroaminoto Palopo.

Indan. 2003. Mikrobiologi dan Parasitologi. PT. Citra Aditya Bakti. Bandung.

Katiho, A.S., Joseph, W.B.S.,dan Malonda, N.S.H. 2013. Gambaran Kondisi Fisik Sumur Gali di Tinjau dari Aspek Kesehatan Lingkungan dan Perilaku Pengguna Sumur Gali di Kelurahan Sumompo Kecamatan Tuminting Kota Manado: Fakultas Kesehatan Masyarakat Universitas Sam Ratulangi. Manado. 
Soemirat. 2009. Kesehatan Lingkungan.

Gadjah Mada University Press.

Yogyakarta.

Suryana. 2013. Analisis Kualitas Air Sumur Dangkal di Kecamatan Biringkanayya Kota Makassar : Fakultas Teknik Universitas Hasanudin Makassar. Tinggi PAU Pangan dan Gizi IPB, Bogor

Waluyo. 2005. Mikrobiologi Umum. UMM. Malang 